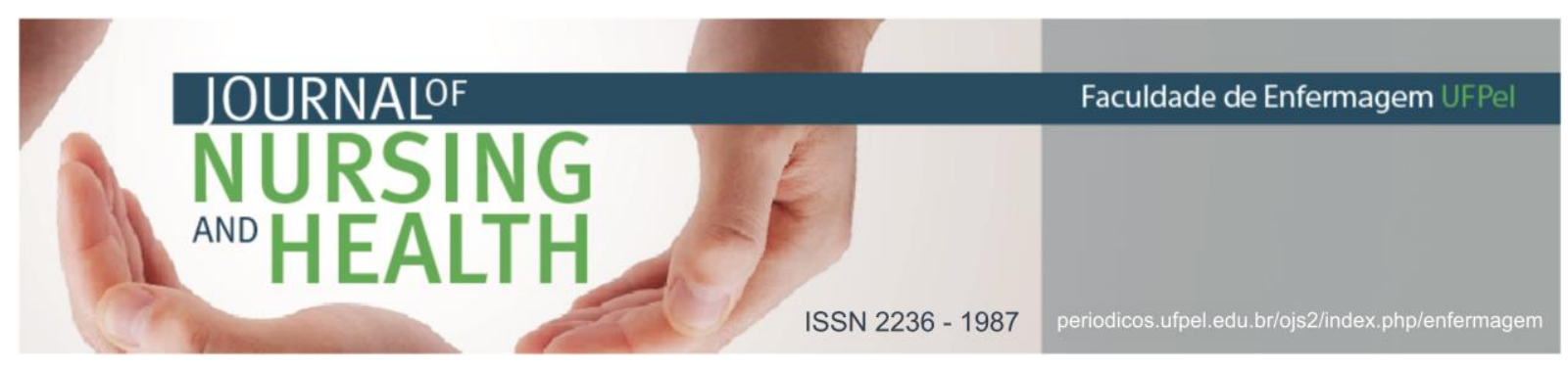

ARTIGO ORIGINAL

\title{
Ouvidores de vozes: relações com as vozes e estratégias de enfrentamento
}

\author{
Voice hearers: relationships with voices and coping strategies
}

\section{Oidores de voces: relaciones con las voces y estrategias de enfrentamiento}

Kantorski, Luciane Prado; Souza, Thylia Teixeira²; Farias, Tais Alves ${ }^{3}$; dos Santos, Luiza Hences ${ }^{4}$; Couto, Maria Laura de Oliveira ${ }^{5}$

Como citar este artigo: Kantorski LP, Souza TT, Farias TA, dos Santos LH, Couto MLO. Ouvidores de vozes: relações com as vozes e estratégias de enfrentamento. J. nurs. health. 2018;8(n.esp.):e188422

\begin{abstract}
RESUMO
Objetivo: abordar a relação que o ouvidor de voz estabelece com suas vozes e as estratégias que estes utilizam no enfrentamento desta experiência. Métodos: pesquisa realizada através da aplicação da Entrevista Estruturada de Maastricht em ouvidores de vozes, proposta em seminário realizado pela Faculdade de Enfermagem da Universidade Federal de Pelotas no período de fevereiro a abril de 2017. Resultados: Das oito entrevistas realizadas seis foram com ouvidores que frequentavam serviços de saúde mental, e duas com ouvidores que não eram acompanhados pelos serviços, cinco mulheres e três homens, com idade entre 40 e 55 anos. A maior parte dos ouvidores relatam ouvir vozes negativas, dentre as estratégias utilizadas estão ignorar as vozes, dialogar com elas ou com familiares a respeito delas. Considerações finais: para estabelecer uma boa relação diária com as vozes é necessário reconhece-las como parte do indivíduo, bem como encontrar estratégias de enfrentamento.

Descritores: Psiquiatria; Esquizofrenia; Alucinações.
\end{abstract}

\section{ABSTRACT}

Objective: to address the relationship that the voice hearers establishes with their voices and the strategies they use to cope with this experience. Methods: this study was carried out through the application of the Maastricht Structured Interview in voice hearers, proposed at a seminar held by the Nursing School of the Federal University of Pelotas from February to April 2017. Results: of the eight interviews, six were conducted with voice hearers that were attended in mental health services, and two voice hearers were not accompanied by the services, five women and three men, aged between 40 and 55 years. Most listeners report hearing negative voices, among the strategies

\footnotetext{
1 Enfermeira. Doutora em Enfermagem. Universidade Federal de Pelotas (UFPEL). E-mail: kantorski@uol.com.br http: / / orcid.org/0000-0001-9726-3162

2 Graduanda de Enfermagem. Bolsista de Iniciação Científica PIBIC - CNPq. Universidade Federal de Pelotas (UFPEL). E-mail: thyliasouza@hotmail.com http://orcid.org/0000000270860853

3 Graduanda de Enfermagem. Bolsista de Iniciação Científica PIBIC - CNPq. Universidade Federal de Pelotas (UFPEL). E-mail: h_luiza@live.com http://orcid.org/0000000207748463

4 Graduanda de Enfermagem. Bolsista de Iniciação Científica PIBIC - CNPq. Universidade Federal de Pelotas (UFPEL). E-mail: tais_alves15@hotmail.com http://orcid.org/0000000223072491

5 Psicóloga. Universidade Federal de Pelotas (UFPEL). E-mail: marialauradeoliveiracouto@gmail.com http: / / orcid.org/0000-0002-5103-3000
} 


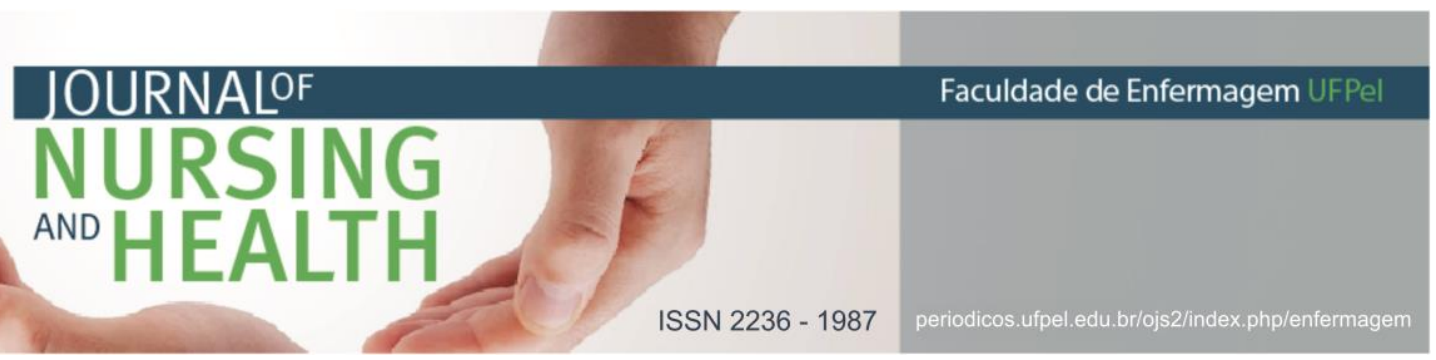

used are ignoring voices, talking to them or relatives about them. Final considerations: to establish a good daily relationship with the voices is necessary to recognize them as part of the individual, as well as finding coping strategies.

Descriptors: Psychiatry; Schizophrenia; Hallucinations.

\section{RESUMEN}

Objetivo: abordar la relación que el oidor de voz establece con sus voces y las estrategias que estos utilizan en este enfrentamiento. Métodos: investigación realizada por la aplicación de Entrevista Estructurada de Maastricht en oidores de voces, propuesta en el seminario realizado por la Facultad de Enfermería de la Universidad Federal de Pelotas de febrero a abril de 2017. Resultados: de las ocho entrevistas realizadas, seis fueron con oidores que frecuentaban servicios de salud mental y dos con oidores que no eran acompañados por los servicios, cinco mujeres y tres hombres, entre 40 y 55 años. La mayoría de los oidores relata oír voces negativas, entre las estrategias más utilizadas están ignorar las voces, dialogar con ellas o con familiares sobre ellas. Consideraciones finales: para establecer buena relación diaria con las voces es necesario reconocerlas como parte del individuo y encontrar estrategias de enfrentamiento.

Descriptores: Psiquiatría; Esquizofrenia; Alucinaciones.

\section{INTRODUÇÃO}

Desde os primórdios, o fenômeno de ouvir vozes é conhecido como sinônimo de doença e loucura, sendo sempre associado à esquizofrenia e à crença de que não haveria um tratamento suficientemente eficaz, capaz de proporcionar aos indivíduos uma vida cotidiana "normal". 1 Costuma ser uma experiência perturbadora, que muitas vezes perdura por um longo tempo, apesar dos esforços terapêuticos. ${ }^{2}$

Habitualmente, não é uma experiência da qual se compartilha, pois socialmente é estigmatizada e indesejada, sendo sua prevalência em todo o mundo de $4 \%$ a $10 \% .{ }^{3}$ Sendo do total, $2 \%$ a $4 \%$ da população adulta, que as vozes não são em si mesmas um sinal de doença. ${ }^{4}$

\section{Pesquisas apresentaram} conclusivamente que vozes estão exprimindo, pelo que elas falam e pelo modo que interagem com o ouvidor de voz, aquilo que aconteceu na vida desta pessoa, sendo claro que as experiências traumáticas constituem parte importante do desenvolvimento das experiências de ouvir vozes. ${ }^{3}$

Se a origem das vozes é um trauma, o medo está presente a todos e a exigência de compreender. 0 medo que se caracteriza nesta fase do princípio da experiência, está ligada à construção social, relacionando-se as vozes à loucura e à esquizofrenia, e ao pavor de ouvir vozes que outros não escutam. Essa experiência solitária é quase proibida de ser partilhada, fazendo com que o ouvidor de vozes reconheça a experiência como algo assustador. . $^{5-6}$

Embora a experiência de ouvir vozes possa acarretar muitas limitações no cotidiano das pessoas, como dificuldade de estabelecer vínculo empregatício, convívio familiar, estigmas sociais e preconceitos, muitos ouvidores acabam criando estratégias que tornam essa experiência menos penosa, conseguindo vencer esses 
obstáculos, e por vezes até mesmo estabelecer boas relações com as vozes. ${ }^{7}$

Torna-se importante explorar as ligações entre as vozes, o trauma e as emoções envolvidas que se encontram nas raízes da experiência dos ouvidores, aprendendo a lidar com estas emoções e para o seu processo de recuperação. Sendo relevante a compreensão que as vozes servem como um mecanismo de defesa, evitando o confronto com esses problemas e as emoções envolvidas. $\mathrm{E}$ lidar com esses problemas e emoções é necessário para levar uma vida plena. ${ }^{8}$

Este estudo tem como objetivo abordar a relação que o ouvidor de voz estabelece com suas vozes e as estratégias que estes utilizam no enfrentamento desta experiência.

\section{MATERIAIS E MÉTODOS}

Trata-se de uma pesquisa qualitativa em que os dados foram coletados durante o curso "Seminário: Ouvidores de Vozes - movimento, experiências e práticas" ofertado para profissionais, ouvidores de vozes e acadêmicos de graduação e pósgraduação pela Faculdade de Enfermagem da Universidade Federal de Pelotas. Neste curso foi proposto que os participantes aplicassem a Entrevista Estruturada de Maastricht ${ }^{9}$ em ouvidores de vozes que eles tivessem acesso, tanto nos serviços de saúde mental quanto nos seus meios sociais. A Entrevista Estruturada de Maastricht foi desenvolvida por Marius Romme, Sandra Escher e Patsy Hage na Holanda.
O curso foi ministrado no período de fevereiro a abril de 2017 sendo realizado uma vez por semana com duração de quatro horas. Foram realizadas oito entrevistas pelos participantes, as quais foram gravadas e transcritas na íntegra. Dessas, seis entrevistas foram realizadas com ouvidores que frequentavam serviços de saúde mental, e duas com ouvidores que não tinham acompanhamento. Além das entrevistas, foram utilizadas anotações realizadas em diário de campo.

A pesquisa atendeu a todos os requisitos éticos previstos na Resolução $n^{\circ} 466$ de 12 de dezembro de 2012 que dispõe da proteção de vida aos participantes de pesquisas científicas envolvendo seres humanos. ${ }^{10}$

Os dados obtidos integram 0 projeto de pesquisa denominado " $\mathrm{A}$ constituição de práticas sociais "desinstitucionalizantes" no contexto das reformas psiquiátricas brasileira e italiana", o qual foi aprovado pelo Comitê de Ética em Pesquisa sob o parecer $n^{\circ} 750.144$ de 2014 da Faculdade de Medicina da Universidade Federal de Pelotas.

Os dados das entrevistas foram analisados com foco nas temáticas: relações com as vozes e estratégias de enfrentamento.

\section{RESULTADOS E DISCUSSÃO}

\section{Relações com as vozes}

Os achados nas entrevistas demonstram relações negativas e positivas com as vozes, sendo a maioria negativa, principalmente por parte dos 


\section{NURSING \\ NNO HEALTH}

ISSN 2236 - 1987

ouvidores de vozes que fazem acompanhamento em serviços de saúde mental. Apresentadas nas falas a seguir:

A Voz negativa sempre pede para fazer alguma coisa contra mim mesma, para me matar, para cortar os pulsos, para tomar clorofina. (Ouvidora 2)

Vozes dizendo que eu me mate que sou inútil, que não tem nada para eu fazer aqui, que não me sinto feliz, então não vale a pena viver. São sempre vozes que me humilham e incomodam. (Ouvidor 7)

São muitas vozes ao mesmo tempo tanto que parece muitas vezes mais com ruídos porque não consigo discernir, são vozes de homem, de mulheres $e$ de criança. Outra coisa que me incomoda muito é a sensação quando passa alguma coisa do meu lado que faz um barulho, tem o som e um barulho e uma sensação de movimento que não sei o que é. Tenho muito medo por isso. (Ouvidor 4)

De acordo com pesquisa realizada, a pessoa que ouve vozes de conteúdo negativo aumenta a probabilidade de ter uma resposta emocional negativa, de ter contato com os serviços de saúde mental e serem mais propensas a ter vozes que falam ou discutem entre si e que comentam sobre eles. Além destas vozes permanecerem por períodos mais longos, perturbarem o contato com outras pessoas, assumirem seus pensamentos elas tendem a ter menos controle sobre as vozes. ${ }^{11-12}$

Diversificadas são as razões que podem levar um indivíduo a possuir uma relação negativa com suas vozes. Primeiro pela descoberta ou início das alucinações auditivas, denominadas como uma experiência assustadora, depois por fatores que oferecem para os ouvidores de vozes o desconhecimento do que está acontecendo naquele período que as vozes se mostram presentes e também por traumas ou abusos geralmente ocorridos na infância, que aumentam as reações emocionais e psicológicas demonstrando anormalidades na resposta a situações estressantes na fase adulta. ${ }^{13}$

Em vista do que foi referido pelos autores, observa-se nas falas que alguns entrevistados também referiram desenvolver experiências positivas com relação à escuta das vozes, como citadas a seguir:

As vozes são uma produção minha, mas que governam em mim são minhas companheiras mesmo havendo aspectos ruins em ouvi-las, mas também são recados que coincidem com fatos, por isso não consigo pensar que seja necessariamente só produção minha, que é ingovernável. (Ouvidora 3)

Essa voz é o homem dos meus sonhos e sou apaixonada por ele desde os doze anos de idade. [...] hoje ele fala e eu escuto baixinho, ele diz que está apaixonado e que me ele ama e que é para eu esquecer o que 


\section{ISSN 2236 - 1987}

aconteceu no passado comigo e o meu pai. (Ouvidora 5)

o meu irmão diz que normalmente são coisas de proteção mesmo, não tem nenhuma experiência que seja negativa. (Ouvidora 8)

As pessoas que ouvem vozes positivas são significativamente mais propensas a influenciar suas vozes. Percebe-se que há o entendimento e a aceitação de que as vozes pertencem ao ouvidor e que estão relacionadas às suas histórias de vida e que de fato são reais. Dar sentido às vozes envolve reconhecer a existência de uma relação entre as vozes e as experiências traumáticas no intuito de adquirir informações sobre os eventos da vida e a sua relação com as vozes. ${ }^{12-}$ 13

As relações são positivas quando as vozes proveem do meio externo relacionado ao ouvidor, já que se apresentam menos enraizadas ou patológicas, expressando menores sensações nos ouvidores do que as vozes originadas internamente. $\mathrm{E}$ conforme o maior convívio com as vozes e idealizações formadas pelos próprios ouvidores de vozes, essas relações podem tornar-se positivas $\mathrm{e}$ melhor compreendidas. ${ }^{14}$

Estimular o ouvidor de vozes a familiarizar-se mais com a voz gera um aprendizado progressivo de conhecimento desta voz, enquanto possibilita que o ouvidor compartilhe sua experiência com outras pessoas. Falando da sua experiência de audição de vozes o ouvidor reduz a ansiedade e a frequência com que elas surgem e por fim, o mesmo acostuma-se com sua presença. Falar das características das vozes propicia obter mais esclarecimentos sobre os sentidos que são produzidos na vida cotidiana deste ouvidor. ${ }^{4}$

\section{Estratégias de enfrentamento}

Os resultados encontrados mostram estratégias que auxiliam estes ouvidores a estabelecer relações menos estressantes e conturbadoras com as vozes como ficar sozinho ou isolar-se, conversar com familiares ou amigos como forma a desviar a atenção das vozes, pedir para que as vozes cessem, além de tampar os ouvidos para que as vozes diminuam destacadas nas falas a seguir:

Saio e não fico sozinho, mesmo que caminhando sem ter nenhum lugar para ir, sinto que quando estou no meio de outras pessoas a voz diminui. (Ouvidor 7)

Muitas vezes converso com as vozes no sentido de agradecer ou de refutar o que essas vozes dizem, para muitas vezes também tentar silencia-las. (Ouvidora 3)

Chego a tapar o ouvido para que cessem. (Ouvidor 2)

Prejudicam enchendo a minha cabeça a ponto de que eu me isole para que elas diminuem. (Ouvidor 1)

Tenho muito medo de me aprofundar e de querer conversar $e$ do que a voz vai dizer, tenho medo que piore. Tenho a 
sensação de que se eu conversar vai ficar pior. (Ouvidor 4)

Muitas vezes eu ignoro as vozes, quando está de mais, quando não consigo me concentrar em outras coisas. (Ouvidora 6)

Os impactos de ouvir vozes podem afetar diferentes pessoas em diferentes graus, tendo variações da adoção de estratégias para lidar com as vozes. A estratégia muitas vezes pode ser eficaz para uma pessoa e não para outra, sendo importante que os ouvidores de vozes conheçam mais sobre suas próprias estratégias e expandir seu repertório ao longo do tempo. ${ }^{15}$

A abordagem a respeito de conversar com as vozes como uma experiência real na vida do ouvidor, sem haver uma classificação desta experiência como uma expressão de um processo de adoecimento, ou religioso, mas sim em um contexto mais amplo de narrativas pessoais e de sentidos para aqueles que as vivenciam. ${ }^{6}$

Alguns ouvidores utilizam o silêncio como ferramenta no combate às vozes e ignoram-nas, ignorar as vozes não é eficaz, em contrapartida é possível estabelecer um diálogo com as vozes, superando o medo e possibilitando as conhecer e controlar, escrever o que as vozes falam é uma opção de estratégia, que pode ser feita em forma de exercício ou diário, compartilhar a experiência em um grupo de ouvidores de vozes também pode ser benéfico ao ouvidor. ${ }^{6}$

Os grupos de ouvidores de vozes trazem como objetivo construir um relacionamento e reconhecer as vozes como parte da vida cotidiana, encontrar um processo de aprendizagem para lidar com as vozes proporcionando o auto empoderamento e aceitação e uma sensação de que não se está sozinho além de ser um lugar seguro para falar sobre as vozes. ${ }^{3}$

Devido ao auto estigma e preconceitos impostos pela sociedade que reforçam aos ouvidores de vozes o rótulo de "doentes mentais" ou sua experiência associada apenas como loucura, suas relações e estratégias com as vozes tornam-se difíceis. Sendo importante para o ouvidor participar dos grupos de ouvidores de vozes, a fim de estabilizarem suas emoções ao expressarem seus impasses e sentimentos em grupo, desmistificando sua situação e excesso de medicamentos que acabam barrando seus sentidos. Assim, fazendo com que consigam direcionarem melhor suas vidas, através de maior autonomia e compreensão de fatores que norteiam sua realidade. ${ }^{16}$

\section{CONSIDERAÇÕES FINAIS}

As vozes além de serem disparadas por situações traumáticas refletem a realidade vivenciada pelo ouvidor, não raras vezes a intensidade e tipo de voz traduzem um sentimento enrustido, quando frequentes e negativas as vozes podem expressar decisões erradas ou momentos depressivos na vida do ouvidor, assim como vozes amenas e positivas podem indicar um estado de paz e tranquilidade vivenciado pelo ouvidor naquele momento.

Enfrentar a fase da surpresa, negar e ignorar as vozes fazem parte 


\section{JOURNALOF \\ NURSING \\ ANO HEALTH}

ISSN 2236 - 1987

S0103-

73312017000400867\&script=sci_abstra ct\&tlng=pt

3 Baker P. Abordagem de ouvir vozes: treinamento Brasil. Tradução de Lindsei Ferreira Lansky. São Paulo: CENAT; 2016.

4 Romme M, Escher S. Na companhia das vozes: para uma análise da experiência de ouvir vozes. Lisboa: Editorial Estampa; 1997.

5 Kantorski LP, Andrade APM, Cardano, M. Estratégias, expertise e experiências de ouvir vozes: entrevista com Cristina Contini [Internet]. Interface comunic saude educ. 2017[cited 2018 Mar 26]; 21(63):103948. Available from: https: / /www.scielosp.org/article/ssm /content/raw/?resource_ssm_path=/ media/assets/icse/v21n63/1807-5762icse-21-63-1039.pdf

6 Kantorski LP, Antonacci MH, Andrade APM, Cardano M, Minelli M. Grupos de ouvidores de vozes: estratégias e enfrentamentos [Internet]. Saúde debate, 2017 out-dez[acesso em 2018 mar 26]; 41(115):1143-55. Disponível em:

http://www.scielo.br/scielo.php?scrip $\mathrm{t}=\mathrm{sci}$ arttext\&pid=S0103-

11042017000401143

7 Muñoz NM, Serpa-Júnior OD, Leal EM, Dahl CM, Oliveira IC. Pesquisa clínica em saúde mental: o ponto de vista dos usuários sobre a experiência de ouvir vozes [Internet]. Estud psicol. 2011 [acesso em 2018 mar 26];16(1):83$9 . \quad$ Disponível em: http://www.scielo.br/pdf/epsic/v16n 1/a11v16n1.pdf

8 Romme M, Escher S, Dillon J, Morris $M$, Corstens D. Living with voices: 50 


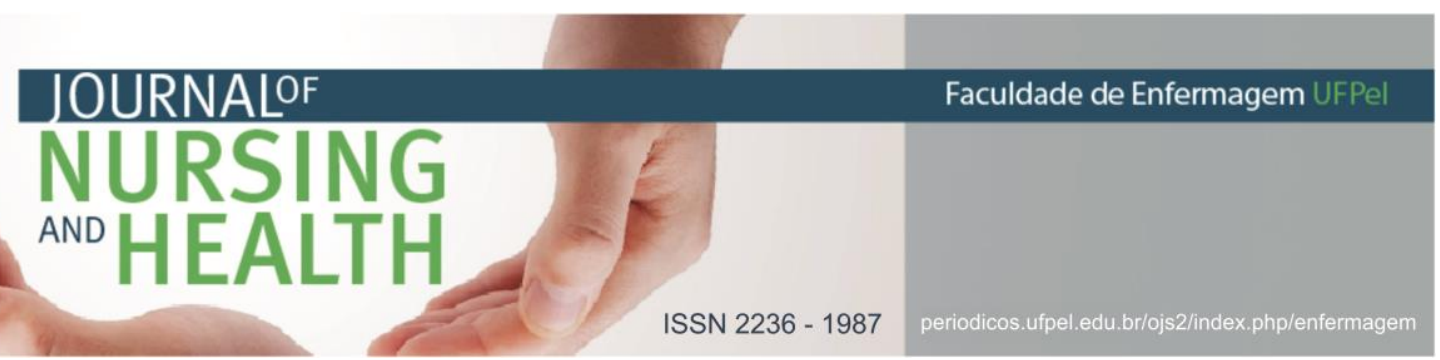

stories of recovery. Monmouth: PCCS Books; 2009:346.

9 Romme M, Escher S. Making sense of voices: a guide for mental health professionals working with voicehearers. London: Mind Publications; 2000: 143.

10 Ministério da Saúde (BR). Conselho Nacional de Saúde. Resolução 466, de 12 de dezembro de 2012: diretrizes e normas regulamentadoras de pesquisa envolvendo seres humanos. Brasília; 2012.

11 Beavan V, Read J. Hearing voices and listening to what they say the importance of voice content in understanding and working with distressing voices [Internet]. J nerv ment dis. 2010[cited 2018 Mar 26]; 198(3):201-4. Available from: https://insights.ovid.com/pubmed?p mid $=20215997$

12 Woods A, Jones N, Alderson-Day B, Callard F, Fernyhough C. Experiences of hearing voices: analysis of a novel phenomenological survey [Internet]. Lancet psychiatry. 2015[cited 2018 Mar 26]; 2:323-31. Available from: https: / / www.thelancet.com/action/s howPdf?pii=S2215-

0366\%2815\%2900006-1

13 Sheffield JM, Williams LE, Blackford JU, Stephan Heckers S. Childhood sexual abuse increases risk of auditory hallucinations in psychotic disorders [Internet]. Compr psychiatry. 2013[cited 2018 Mar 26]; 54(7):1098104. Available from: https: //www.ncbi.nlm.nih.gov/pubm ed/23815887

14 Docherty NM, Dinzeo TJ, Mccleery A, Bell EK, Shakeel MK, Moe A. Internal versus External Auditory Hallucinations

in Schizophrenia: Symptom and Course Correlates [Internet]. Cogn neuropsychiatry. 2015[cited 2018 Mar 26]; 20(3):187-97. Available from: https://www.ncbi.nlm.nih.gov/pmc/a rticles/PMC4372463/

15 Ng P, Chun RK, Tsun A. Recovering from Hallucinations: A Qualitative Study of Coping with voices hearing of PEOPLE with schizophrenia in Hong Kong [Internet]. The scientific world journal. 2012[cited 2018 Mar 26];8. Available from: https: / /www.hindawi.com/journals/t swj/2012/232619/

16 Barbero MAM, Pereira MCC, Villalba GP, Hernández MVM. Escuchando la voz de las personas que escuchan voces [Internet]. Rev asoc esp neuropsiquiatr. 2017[acceso $2018 \mathrm{mar}$ 26];37(131):39-61. Disponible en: http://www.revistaaen.es/index.php/ aen/article/view/16989

Data de publicação: 19/09/2018 